IBIMA Publishing

Journal of Internet Social Networking and Virtual Communities

http://www.ibimapublishing.com/journals/JISNVC/jisnvc.html

Vol. 2014 (2014), Article ID 977265, 26 pages

DOI: $10.5171 / 2014.977265$

Research Article

\title{
Social CRM: A Business Case for the Irish Health Insurance Industry
}

\author{
Jayadev Vallath ${ }^{1}$ and Paula L. Roberts ${ }^{2}$ \\ ${ }^{1}$ VHI Healthcare, Dublin 1, Ireland \\ ${ }^{2}$ School of Computer Science \& Statistics, Lloyd Institute, Trinity College,Dublin 2, Ireland \\ Correspondence should be addressed to: Jayadev Vallath; jayadevvallath@gmail.com
}

Received date: 13 September 2013; Accepted date: 18 July 2014; Published date: 31 October 2014

Academic Editor: António Eduardo Martins

Copyright (C) 2014. Jayadev Vallath and Paula L. Roberts. Distributed under Creative Commons CC-BY 3.0

\begin{abstract}
Social Customer Relationship Management (Social CRM) is emerging as a major initiative for a number of organisations due to its appeal as a new channel of communication as well as its effectiveness as a customer engagement tool. Though there is growing acceptance of Social CRM, many organisations are not entirely convinced of its suitability due to the difficulty in justifying the Business Case. This paper introduces a framework for validating its Business Case. It is observed that some industries are more suited to Social CRM due to the nature of the business, customer profile and a number of other external factors. This paper focuses on the Irish Health Insurance Industry as a specific example and explores relevant external environmental factors which can influence the Social CRM business case. The research was carried out by studying the existing literature to identify relevant topics which were then analysed based on the current market situation. A team of experts assisted in validating the study and arriving at the level of influence. The research confirms that nine out of the ten external environmental factors examined positively influence the business case for Social CRM.
\end{abstract}

Keywords: Social CRM, CRM, Social Media, Health Insurance

\section{Introduction}

The Irish Health Insurance Industry has been going through a difficult phase in recent periods due to the economic recession. For the first time since the introduction of Private Health Insurance In Ireland, the year 2009 reported a reduction in the percentage of people insured by private insurers (The Health Insurance Authority, 2009) and this resulted in a reported loss of $22 \%$ in the premium income and a decrease of $83 \%$ in underwriting profit (Simon, 2009). This pattern has continued to date with the current percentage of the population with inpatient health insurance plans currently standing at $45 \%$, down from the 2008 peak of $51 \%$ (The Health Insurance Authority, 2014).

Serious questions were also raised on the efficacy of Ireland's Private Health Insurance system which is based on a Community Rating System (McDonnell and O'Donovan, 2009). The discussion in

Cite this Article as: Jayadev Vallath and Paula L. Roberts (2014), " Social CRM: A Business Case for the Irish Health Insurance Industry ", Journal of Internet Social Networking and Virtual Communities,

Vol. 2014 (2014), Article ID 977265, DOI: 10.5171/2014.977265 
political circles on introducing the Dutch model of Universal Health Insurance instead of the current Voluntary Health Insurance Model (Buckley, 2010) also touched the core issue of the sustainability of the current model of Private Health Insurance in Ireland.

The economic downturn combined with uncertainty in the regulatory environment is intensifying the competition in the industry, yet the number of people insured is steadily declining. In this highly volatile environment, capturing and retaining the most profitable market segments such as the young policy holders and employer sponsored groups are important for the survival of the Insurance providers. This paper explores how Social CRM with its innovative and dynamic approach can impact the Irish Health Insurance Industry in the current market situation.

\section{Private Health Insurance in Europe}

Healthcare in Europe is largely funded by the Government by way of tax financing or social health insurance and the scope and nature of this publicly financed component mainly determines the private health insurance that develops in a country (Mossialos, 2002). Private health insurance is mainly used in these countries for providing substitutive, supplemental or complementary health care. Substitutive private insurance cover is in demand in countries where a section of people are excluded from public cover and are dependent on private cover; for instance, high income category people in Germany and Netherlands (Schneider, 2012),(Thomson \& Mossialos,2010). Where there is an inordinate delay in access to consultants, a situation akin to Ireland, people buy supplementary insurance cover to get quicker access (Ferral, 2009). In the United Kingdom, supplementary private insurance is purchased by people as it can bring better accommodation facilities in hospitals over and above what is offered by public cover (Foubister et al, 2006), (Ferral, 2009). Complementary health insurance is purchased by people for availing services that are excluded or not fully covered by the statutory health care system. An example for this would be Dental care and
Physiotherapy cover in the Netherland (Maarse, 2011).

There are mainly three ways private health insurance premiums are paid. It can be paid by

1. an individual

2. shared between the employees and the employer

3. or paid wholly by the employer.

For calculating premiums, insurance companies follow a risk rating model which can be

- individual risk rating

- community rating

- or, experience rating (also called group rated).

Risk rating in individual health insurance segment is done by placing individuals into different risk categories based on various identifiable personal characteristics, such as age, gender, occupation and prior illness (Bertko, 2008), (Santerre \& Neun 2012). In certain markets, experience rating is used in large companies where employees are priced solely on the basis of claims experience (claims history) for the previous year and all employees within the company are charged the same premium (Bertko, 2008). In community rating, an insurer charges all people covered by the same type of health insurance policy the same premium without regard to age, gender, health status, occupation or other factors

Since health insurance claim costs are considerably more for older members, a community rated system can operate efficiently only if younger members join the health insurance schemes to provide the resources to support the elderly and chronically ill through cross-subsidisation (Department of Health and Children, 1999). In a community rated market, absence of this intergenerational support will result in unaffordable insurance premium and eventual collapse of the business (Mechanic et al., 2005), (Percy, 2000), (Buchmueller and Dinardo, 2002). A Community Rated system is generally accompanied by some form of risk equalisation to compensate insurers who carry higher risk in their books by insuring a larger percentage of elderly members (The OECD Health Project, 2004). 


\section{Risk Equalisation in Private Health Insurance in Ireland}

Though Ireland introduced Risk Equalisation in 2003, this was rejected by the Supreme Court in 2008 on technicalities (Independent, 2008). This forced the Government to introduce an interim "loss compensation" scheme to bring stability to the market (Department of Health and Children, 2010) though this scheme, in its present form, is considered only $40 \%$ effective (Dones, 2010) In this highly volatile environment, capturing and retaining the most profitable market segments such as the young policy holders and employer sponsored groups become all the more important for the survival of the insurers. The Society of Actuaries in Ireland had warned, as early as in 2002, that the competition for young new entrants or for employer sponsored group schemes will be strongest in an environment without risk equalisation (John et al., 2002). The following observations by Health Insurance Authority in its submission to Government are particularly relevant here in understanding the current market sentiment (The Health Insurance Authority, 2009).

- New health insurance consumers and switchers will tend to be younger and healthier.

- Older and unhealthy consumers will tend to be extremely unprofitable and less likely to switch insurance provider.

- The incentive for insurers to segment risks so that older and unhealthy customers are sold products that cost more or include a lower level of benefits.

- Insurers are incentivised to design and market products so as to select better risks.

- Insurers with favourable risk profile have a marked competitive advantage.

This research looks at the business case for Social Customer Relationship Management in this business context.

\section{Social Customer Relationship Management}

Social Customer Relationship Management (Social CRM) is defined as a philosophy and a business strategy, supported by a technology platform, business rules, workflow, processes, and social characteristics, designed to prepare sellers for the best conversation and engage the customer in a collaborative conversation in order to provide mutually beneficial value in a trusted and transparent business environment (Schleifer, 2012). Customer engagement using Social Media (Social CRM) is rapidly gaining momentum. According to a survey conducted by Cone Business in social media study, $60 \%$ of Americans use social media, with $59 \%$ of users interacting with organisations on social media sites. $93 \%$ of social media users feel organisations should have a social media presence and 53\% admit feeling stronger connection with organisations when they do have them (Cone, 2008). Ofcom's (2008) research on Social Networking attitude, behaviours and use has shown the growing popularity of Social Network among the younger population; a market segment the Irish Health Insurance Industry should be keen to target and hence benefit from using Social CRM.

\section{Difference between traditional CRM and Social CRM}

CRM is implemented by organisations, mainly as a strategy for managing and nurturing its interactions with its current and prospective customers (Brown, 2000). In traditional CRM, marketing communication and advertisements are directed from company to customers, whereas a more socially active customer would expect to see conversation and engagement from organisations in which they could also participate. Similarly, in traditional CRM, organisations target specific customers through campaign management which limits its scope in comparison to Social CRM which can reach a larger number of potential customers. In traditional CRM, companies are required to contact customers directly to receive feedback, whereas a socially active 
customer can share their experience online with a larger group of people. Organisations, active in Social CRM can play a big role in watching this conversation and intervening and supporting when necessary. Many studies in the past have established the limitations of the traditional CRM (Brent, 2009), (Rodi, 2006). Studies by Prahalad and Ramaswami (2000) have also highlighted the importance of multiple channels of interaction as a strategy in customer relationship management.

In the insurance business, traditional CRM like call centre model CRM also has limitations in targeting policy holders in Employer Sponsored Group Schemes. This is because, in many such schemes, the employer authorises one of its employees to deal with the insurer on behalf of its employees which limits the insurer's ability to reach out to individual employees directly. The best relationship between the seller and the buyer is called a learning relationship (Joseph Pine et al., 1995). This learning relationship and feedback loop is often missing in employer sponsored segment and as a result the insurer is not certain about the employee's preference of product and service. This would limit their ability to devise appropriate marketing strategies in optimising its offering to the targeted group. Establishing relationship in this segment requires innovative and nonconventional approaches, a feature, Social CRM is generally known for.

\section{A Business Case for Social CRM}

Strategic alignment is an important criterion while developing the Business Case, more so in Social CRM development. According to Gartner (2010), fifty percent of business-led social media initiatives will succeed and this will be characterized by a concerted and collaborative effort between IT and the business. Since this research is looking at the Health Insurance Industry, examining the internal environmental factors which are specific to a single organisation is outside its scope. Instead, what it attempts to do is to examine the external environmental factors which would influence the Social CRM Business Case. Examining the external environmental factors is also beneficial as it will help the planners and strategists in shielding the organisation from its negative effects and seeking ways to exploit the positive ones (Canzer, 2006).

An organization's external environment can be best understood by breaking it down into several basic categories depending upon its mission, the industry in which it competes, the markets in which it sells, and the type of strategies it pursues (Moseley, 2009). This research considers the following ten external environmental factors (Hitt et al., 2007) , (Worthington and Britton, 2009), shortlisted based on their appropriateness for this study, for further examination.

1. Nature of Business

2. Demographic Profile

3. Market Forces

4. Cultural Dimensions

5. Social factors

6. Technological Capabilities

7. Business objectives

8. Cost/Benefit Studies

9. Market trends

10. Issues and Risks

\section{Business Case Analysis Framework}

This research developed a Business Case Analysis framework for consolidating the results generated from this study. This process was aided by investigating a number of business analysis techniques such as SWOT (Strength, Weakness, Opportunity and Threat) and MOST (Mission, Objective, Strategies and Tactics) (Dealtry, 1992, Coyle, 2004, Thompson and Martin, 2010) and further enhancing those ideas to create a framework relevant for this research. The framework operates by submitting the summary of literature reviewed by authors and their own analysis of the market situation to a team of experts individually for their comments. This research enlisted the help of six experts for this process. Three of these experts were selected on the basis of their Social Media research background. The other three experts were selected on the basis of their professional reputation in Irish Health Insurance Industry. The individual comments were then circulated 
to other members in the team and they were asked to rate the level of influence, each of the ten external environmental factors play, on the business case for social CRM. The level of influence could be classified under Negative or Positive and can be further categorised as Weak, Moderate or Strong in a scale of +9 to -9 as given below. The final level of influence was then determined by calculating the average rating submitted by experts.

Table 1: Level of Influence scale used for this research

\begin{tabular}{|l|l|}
\hline Level of Influence & Value \\
\hline Positive Strong & 9 to 7 \\
\hline Positive Moderate & 6 to 4 \\
\hline Positive Weak & 3 to 1 \\
\hline Negative Weak & -1 to -3 \\
\hline Negative Moderate & -4 to -6 \\
\hline Negative Strong & -7 to -9 \\
\hline
\end{tabular}

Though the framework developed in this paper is used to determine the influence of external environmental factors on a Business Case, it has wider applications and can be used in qualitative research which is multi-disciplinary in nature and requires interpreting the information gathered from multiple sources.

\section{Nature of Business}

\section{Literature Review}

It is generally accepted that the health insurance risk can be predicted with a reasonable degree of accuracy for a group or population and insurance provides a mechanism for transferring risk from individual to the group through a risk pooling mechanism which is primarily done on the basis of an individual's health profile (Shi and Singh, 2008). The idea is to maintain a predictable and stable level of risk within each risk pool and set terms of coverage and premium to be charged (American Academy of Actuaries, 2001). According to Karen Eggleston (2000), an insurer has a financial interest in trying to enrol consumers at low risk and to discourage high-risk consumers. Adverse selection happens when a risk pool with a certain risk profile and premium attracts a disproportionate share of people in poor health. This will result in the average cost of the pool going up. If the insurer adjusts the premium to reflect the average cost, it will discourage people with better health from joining the pool causing the average cost of the pool to go up further and further. This distorted competitive dynamic is referred to as the "death spiral" (Mechanic et al., 2005).

Favourable risk selection occurs when healthy people are disproportionately enrolled into a health plan. For example health plans may selectively enrol healthier people and avoid sicker ones, or they may induce risk selection through selective advertising and product design (Eggleston, 2000). Since patients with chronic health problems are likely to consume more services, risk selection can help insurers to increase their profitability. It has been estimated that the most expensive $1 \%$ of the population, the very sick, accounts for $30 \%$ of all health spending, and the least expensive $50 \%$ of the population, the healthy, accounts for only 3\% of health spending (Shi and Singh, 2008). In order to avoid such situations, insurers often have multiple risk pooling arrangements for different markets such as individuals, family, small businesses and trade associations. Insurers also design different benefit plans within markets such as plans with different levels of premium. This product differentiation protects the insurers because problems in one risk pooling arrangement will not have a direct effect on people participating in another pooling arrangement (Claxton, 2002).

In a risk rated market, individuals are charged premiums based on their health profile, whereas in a community rated market a single rate is charged to all 
customers for a given level of coverage which generally reflect the average costs to its community of subscribers for each type of policy (Hall, 1994). Community rating prevailing in Ireland is based on Open Enrolment and 'Life Time Coverage' which force insurers not to refuse coverage (McDonnell and O'Donovan, 2009) and require them to charge the same premium regardless of age, gender, sexual orientation or current or prospective health status (Barrett, 2000). 'Lifetime coverage' also ensures that once insured, subscribers cannot be refused renewed coverage (McDonnell and O'Donovan, 2009). For the insurer, community rating helps in keeping down the administrative cost as there is no need for individual underwriting in a community rated market (PricewaterhouseCoopers, 2006).

Community rating is usually accompanied by open enrolment and compulsory insurance (Kifmann, 2002), though in Ireland, it is voluntary and does not require everyone to purchase Health Insurance. In Australia, where Private Health Insurance is voluntary, adverse selection resulted in death spiral type of situation, forcing the Government to introduce an age based penalty scheme (Connelly and Brown, 2010). Age based penalty creates an incentive for younger generation to take Health Insurance early as those who join after a certain age are penalised with higher premium. In certain countries, everyone is required to take Health Insurance which will help in bringing down the average cost of health insurance coverage. The Netherlands is one such country where the Universal Health Insurance model makes it compulsory for people to take private health insurance for curative and primary care (Rosenau and Lako, 2008) .

Risk equalisation is an important concept in community Rated Health Insurance market. Its objective is to equalise the risk profiles experienced by different insurers, without equalising the effect of different levels of cost efficiency or underlying profit margins. The concept works by providing for payments to be made to a central fund by insurers who insure relatively low-risk persons. The central fund will then be used to compensate insurers who insure relatively high-risk persons (Kennedy, 1996).

\section{Current Market Analysis}

Many consider the private, public two-tier system followed in Ireland problematic from both efficiency and equity perspectives (Brian, 2006). The country operates a community rated market wherein insurers are required to charge the same premium irrespective of the health status of the enrolee. For the community rated market to operate effectively, a risk equalisation mechanism to spread the risk among the insurers should be in place to neutralise the adverse and favourable selection effect. The present Tax Credit system is merely an interim measure and only partially compensates for the higher risk some insurers carry on account of community rating. As warned by the Society of Actuaries in Ireland, the current situation intensifies the competition for the profitable segments such as young new entrants or for employer sponsored group schemes (John et al., 2002). The system calls for ingenious ways for acquiring and retaining the most profitable segment and this would encourage implementation of Social CRM.

\section{Experts' View on Level of Influence}

Experts are of the view that given the sensitive nature of health insurance, the Industry would need to carefully select the applications of Social CRM that it uses. They do not rate Social CRM as a priority for customer support but think that it has high potential for a marketing and sales campaign.

On the one hand, there is urgency in attracting the most profitable segment in the current market situation. At the same time, the sensitive nature of Health Insurance will require considerable thought in deciding the nature of application and appropriate safeguards in handling privacy and security issues. Taking into account these factors, the experts consider that the Nature of Business will have a Positive, moderate influence in implementing Social CRM. 


\section{Demographic Profile}

\section{Literature Review}

Individual and Group are the two familiar Market segmentations in Health Insurance Industry. Within the Individual Segment, a further classification such as 'Single', 'Couple' and 'Family' policy holders are seen in Irish Health Insurance Industry. A move towards life stage based segmentation is also seen lately. This is common when insurers cannot distinguish between low risk and high risk consumers and consequently offer policies in a "selfselection mechanisms" whereby a policy intended for low risks will have low level of coverage and hence will not be chosen by high risks (Feldman and Dowd, 2000). A similar situation was also be observed in Australia where a proliferation of products each with its own 'community-rated' flat rate was visible to attract particular segments of the market (PricewaterhouseCoopers, 2006).

In Individual market, the insurers need to be cautious about people purchasing health insurance when they expect to have health care needs (Marquis and Buntin, 2006). Previous studies have also established that the low risk individuals tend to purchase less insurance in the individual market (Mark, 1992) resulting in greater possibility for adverse selection. One way to overcome this problem is to design suitably priced diversified products with benefit contents grouped in terms of low and high-risk with a view to separate risks (Chollet, 1998).

Providing coverage to an already formed large group of people, such as the employees of a large employer, reduces the possibility of adverse selection (Claxton, 2002). This is because in group insurance, people enrol in health coverage as a part of their employment rather than when they are sick (Collins, 2007). In addition to underwriting efficiencies, group insurance is also attractive to insurers on account marketing and administrative efficiencies (Kwon and Skipper, 2007). In a group insurance program, substantial number of people in the group will purchase the insurance thorough employer and because of this, the risk is spread out among the insured individuals (Shi and Singh, 2008). Research by Mark J Browne showed that low risk individuals purchase more insurance in groups than in individual health insurance markets making this segment very attractive to the insurer (Mark, 1992). The advantages of group underwriting break down while insuring small employer groups, as there is a possibility that the need for health care by one member of the group is the reason for the group's seeking coverage. This is called the group size factor and it is one of the considerations while underwriting groups (Claxton, 2002).

Individuals purchasing group health insurance through employers limit themselves to the options offered by the employer, though employers generally offer employees a choice of insurer to cater to employees preference for different products (Bundorf, 2010). This is a significant finding for organisations considering Social CRM, as the choice of insurers available to employees should encourage insurers in developing a closer relationship with employees and social media can probably be a suitable channel to reach customers in this segment.

\section{Current Market Analysis}

A market review by Health Insurance Authority in 2008 (Insight Statistical Consulting, 2008) revealed the following results which are of interest to this research. Out of the total policy holders surveyed, $44 \%$ are couples, $26 \%$ retirees and $30 \%$ young singles. What is more interesting for this research is the fact that the singles can be generally described as those who are in 18 to 35 age group having a third level education with a low level of switching and low level of understanding of the cover.

Their age group profile also indicates that this is the most profitable segment and possibly more internet and Social media savvy than the other two segments. The low level of switching would signal that more effort would be needed in acquiring them though retaining them should be relatively easier. This has wide implication for the Social CRM strategy of the organisation in terms of time and effort 
needed to initially attract this segment to build a long term lasting relationship. The low level of understanding of the cover might signify that the main reason for taking the Private Health Insurance is to protect them in the event of a serious illness than for any day to day medical expenses. This might also indicate that this segment is looking for a product which need not have the same attributes required by the other two segments, a possibility that can be of importance to Social CRM in engaging customers in product development suitable for each segment.

The same survey also revealed that in the case of policy holders insured through their employer, $23 \%$ are given a choice of private health insurer by their employer. This means that there is a potential to increase business by influencing this segment through Social CRM channels.

\section{Experts' View on Level of Influence}

Experts agree that Social CRM can be a nonconventional channel for building relationship with customers who otherwise operate through an authorised person from each group. It is also noted that in non subsidised group situations where the employees pay the full insurance premium, Social CRM channel can be a supplementary means operating in tandem with traditional sales channels. In the case of partial or full subsidised group, it can help in building relationship which could be of use in cross selling. In a community rated market, insurers need to offer the same price to the customers irrespective of their risk profile. This can create an impression to the outsiders that there exists only a single market segment in this industry. However, it is true that customer's profitability to the insurer largely depends on their life stage and there is a need to offer appropriate product and services suitable for customer's life stage. In the group segment, literature study shows that larger groups are less prone to adverse selection than smaller groups. There is a growing realisation that it is not a 'one plan fit all' market and appropriate relationship strategy is required to target different market segments. Experts are of the view that Social CRM can be customised to meet different needs of each targeted market segment. These considerations should result in a Positive, moderate score.

\section{Market Forces}

In a community rated market, the competition for attracting low risk group is very high when there is no mechanism for adequate risk equalisation among insurers. Rising medical inflation is another market driver in competing for the low risk segment as medical inflation coupled with a disproportionate share of high risk group customers can have a negative impact on the profitability of the insurer

The research by Warshawsky (1994) shows that the healthcare cost up to the age of 50 stays relatively stable showing only a marginal increase, proportionate to the age. It then increases disproportionately thereafter, costing almost two times more for 50-60 age groups and almost three times more for 60 70 age groups compared to what it costs to insure a 50 year old. The study by Dormont et al (2006) also confirms this increase in health care expenditure with age but also observes a sizable upward drift of the profile between the year 1992 and 2000 . This drift is explained in terms of changes in health care practice resulting in increased use of health care and employing more advanced and expensive technology for better health management.

Generally, technology improvements in a service sector can have a positive effect in reducing the cost of delivering a service. However, this need not be true in the case of health care. This was one of the findings in a study by the US congress office of technology assessment (1984). A similar view was put forward by Brendan Walsh (2002) regarding the situation prevailing in Ireland. Though Walsh agrees that the technical advances have raised the cost of providing health care, he argues that the high labour intensive component in health care and supply demand imbalance in the labour market is also a contributor to this situation. Moreover, the rapid change in the medical care industry, from a traditional voluntary care model to a market driven model has also caused price escalation. An aging population also plays a significant 
role in price escalation because of increased demand for health care.

\section{Current Market Analysis}

The year 2008 saw the Private Health Insurance market share peaking at $52 \%$ in Ireland. This high level of coverage, achieved due to a combination of economic growth, generous tax relief and lack of confidence in the public system, is an exception among supplementary markets which usually cover up to around $10 \%$ of the population (Thomson and Mossialos, 2009). However, for the first time after setting up private health insurance in Ireland, the market size of the population with Private Health Insurance went down in 2009 primarily due to the recession.

This situation has generated intense competition in Irish Health Insurance Industry to reach out to the most profitable segment and has resulted in an unprecedented level of marketing efforts by insurers to persuade prospective customers to switch to one of their plans from a rival plan.

Furthermore, the rate of inflation figures available from the CSO (Central Statistics Office Ireland, 2010) places health as the second highest item of inflation on a consumer price commodity group index. The trend in average insurance claims in Ireland is in tune with the findings from the literature review. Compared to the cost of insuring those who are under 50 years of age, it costs 3 times more to insure those who are in the age group of 60-69, 4 times more to insure those who are in the age group of 70-79 and six times more to insure those who are in the age group of 80 and over. As can be seen from the graph below (Health Insurance Authority, 2010a), the tax credit covers only $40 \%$ of the claim cost for those who are above 50 years.

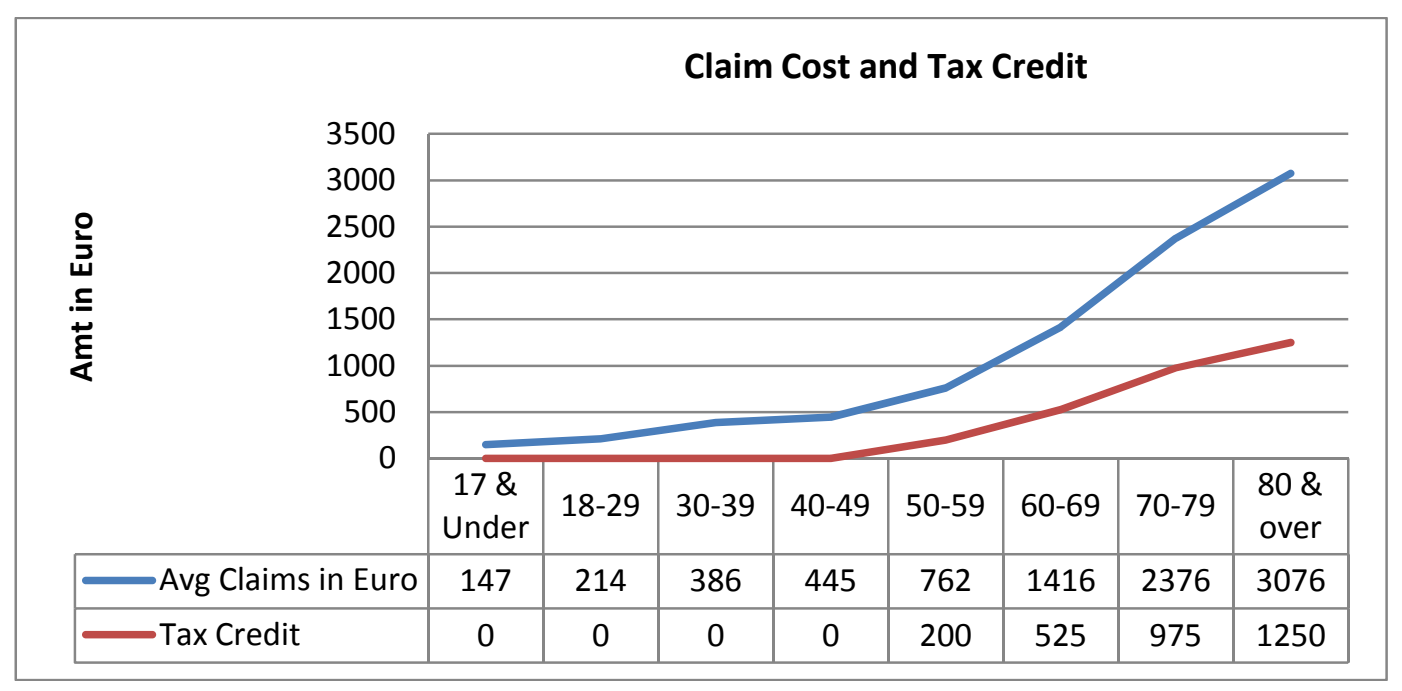

Fig. 1: Claim Cost and Tax Credit

\section{Experts' View on Level of Influence}

A shrinking market and the continuing medical inflation will add financial pressure to the private health insurance business. Considering the claim cost for elder policy holders, the health insurance business can only be sustained by having an appropriate percentage of young policy holders on the books. Insurers need to exploit any avenues which can help them in getting a strong young customer base. It is widely acknowledged (Witter and Chen,
2008) that Social Media attracts younger population (those who are below 50 years old) and this aspect needs to be put to good use. Considering the above facts, experts are of the view that the Market Force will have Positive, strong influence in advancing Social CRM Business Case.

\section{Cultural Dimensions}

Many times, culture plays an important part in strategy formation and this seems to be the case while preparing a Social CRM 
strategy too. This section looks at Greet Hofstadter's research on how the cultural dimensions of a country have an important role to play in developing organisational strategy (Hofstede, 2010, de Mooij and Hofstede, 2010) .

The cultural dimension model developed by Greet Hofstadter is generally recognised as an important guide in understanding the national cultural differences (Hoppe, 2004). The key element of this study is to classify population into the following four main cultural dimensions (Hofstede, 2010):

1. Power Distance Index (PDI). In cultures with small power distance, people relate to one another as equals regardless of formal positions. Cultures with high power distance expect to receive and take orders from authorities (Williams and Zinkin, 2008) and everyone has his or her rightful place in a social hierarchy (de Mooij and Hofstede, 2010). Global brands and luxury articles which can serve the purpose of social status will have a strong appeal in high power distance cultures (Hofstede, 2010) .

2. Individualism (IDV). In Individualistic Cultures, self-actualisation is important. In collectivistic cultures, the identity of people is based on the social system to which they belong and as a consequence it is important to first build a relationship and trust between parties before initiating a transaction (de Mooij and Hofstede, 2010).

3. Masculinity (MAS). In Masculine Cultures, people (whether male or female) value competitiveness, assertiveness, ambiti on, and the accumulation of wealth and material possessions and the dominant values are achievements and success, whereas the dominant values in a feminine society are caring for others and quality of life (Hofstede, 2010). In masculine societies, performance and achievement are important and so are status brands to show one's success (de Mooij and Hofstede, 2010).

4. Uncertainty Avoidance Index (UAI). In Uncertainty Avoidance Culture, people try to avoid uncertainty and ambiguity and control these situations by forming rules and regulations (Hofstede, 2010). People of high uncertainty avoidance are less open to change and innovation than people of low uncertainty avoidance cultures (de Mooij and Hofstede, 2010). They are also less inclined in using e-commerce due to its unknown effect (Khushman et al., 2009).

The following graph based on the data extracted from (Hofstede, 2010) shows Ireland's cultural difference across these four elements in comparison to the European and the World average.

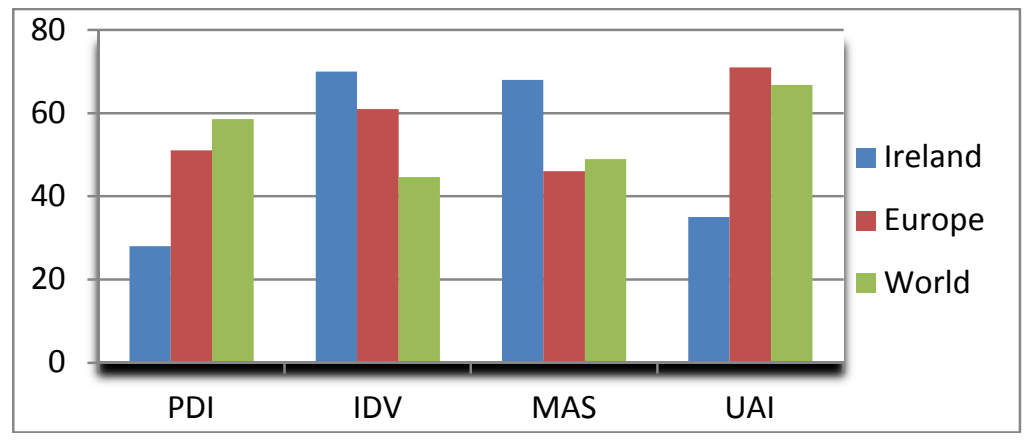

Fig. 2: Ireland's cultural difference in comparison to the European and World average

Ireland has a low PDI and UAI index in comparison to Europe and the world. Cultures with a low UAI index are more open to change and innovation (Hofstede, 2010). In low PDI and UAI cultures, there is a higher propensity on stakeholders to 
expose organisations with irresponsible or bad behaviour and they tend to act in concert through voluntary associations (Williams and Zinkin, 2008). This implies that Ireland has a higher proportion of people who are open to change and innovation, a positive yardstick for companies planning to implement Social CRM, but it also implies that customers will not hesitate to use the same channel for exposing the irresponsible behaviour of the organisation.
In terms of the level of acceptance of Social Networks and Online Communities, Ireland is far ahead of other European countries and United States. As depicted in the following Google Insight graph, the average popularity of Social Networks and Online Communities for the 12 months under study (July 2009 to June 2010) is three times more than the figures available for other countries. Even though the search was repeated for other countries in Europe, it showed up the same pattern. (Note that the graph can show only 5 countries at a time).

\section{Current Market Analysis}

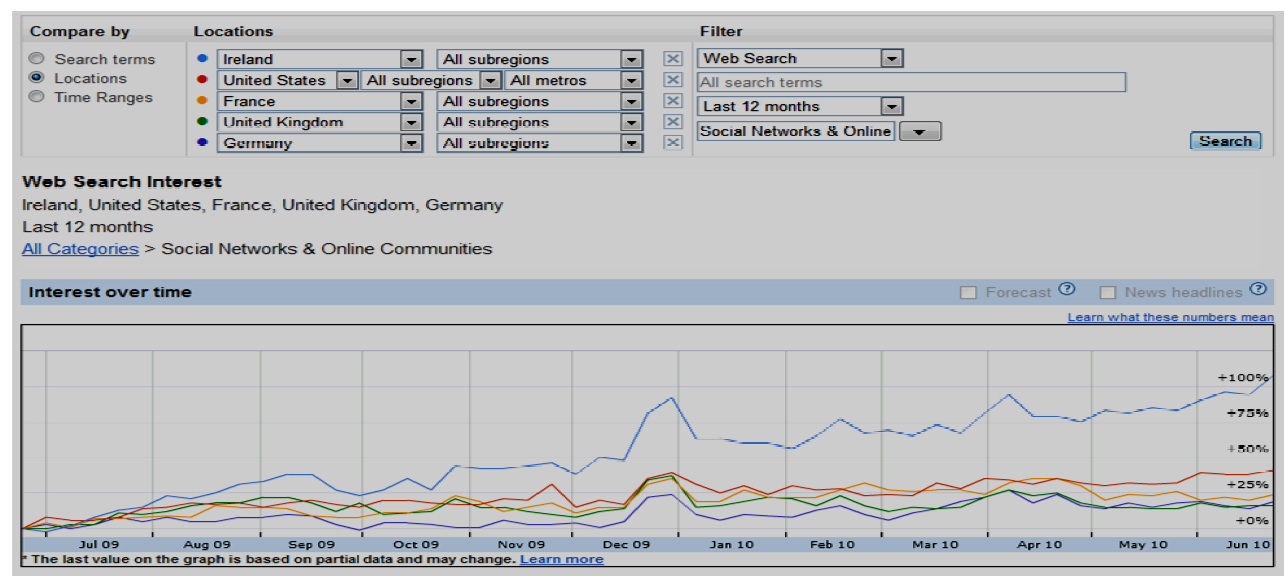

Fig. 3: Popularity of Social Networks and Online Communities

Google Insight also reveals the following figures, specific to some of the popular Social Media sites (Table construed by extracting location-wise numbers from
Google Insights and grouped into a single table for comparing popularity between Social Media sites in selected countries).

Table 2: Popularity between Social Media sites in selected countries

\begin{tabular}{|l|r|r|r|r|r|}
\hline Country & \multicolumn{1}{|l|}{ Twitter } & \multicolumn{1}{l|}{ Linkedin } & \multicolumn{1}{l|}{ YouTube } & Facebook & MySpace \\
\hline Ireland & 66 & 59 & 60 & 62 & 15 \\
\hline United States & 26 & 36 & 13 & 2 & 65 \\
\hline United Kingdom & 13 & 17 & 52 & 83 & 7 \\
\hline Germany & 45 & 44 & 41 & 64 & 13 \\
\hline France & 13 & 6 & 18 & 13 & 7 \\
\hline
\end{tabular}

As can be seen from the above table, Ireland is number one in the usage of Twitter, LinkedIn and Youtube. Its Facebook usage is third in the list and surprisingly way ahead of the United
States. As expected, MySpace is popular only in the United States. The above figures need to be understood within a cultural context and for comparison between countries. It is not a guide in deciding the 
most popular social media channel in Ireland as interest in Facebook exceeds any other social Media Channel (71 to 3) as per a Google Insight Search on Social Media specific to Ireland.

\section{Expert's view on Level of Influence}

The above figures as well as Cultural Dimension studies of Hofstede show a strong Social Network and Online Community culture in Ireland which should result in a Positive, strong influence.

\section{Social Factors}

\section{Literature Review}

The evolution of Social CRM can be linked to the current research on Social Capital and Trust Theories and its adoption by organisations in relationship marketing and subsequent developments in traditional CRM practices. Social Capital is defined as the density of trust between the relevant actors (Svendsen and Svendsen, 2009). Like Physical Capital, Social Capital can produce a stream of benefits to its owner in the form of information sharing, collective decision making and action. Similarly, it requires regular maintenance in the form of repeated social interaction or trust building behaviour (Grootaert and Bastelaer, 2002).

Values, networks and trust have strong effects on Social Capitals. Networks provide members with information and access to other members. A network's ability to increase Social Capital depends on values inherent in the network and trust becomes a precondition for individuals to make an investment in Social Capital (Stickel et al., 2009). In fact, many studies consider 'trust' the key ingredient for maintaining social relationships amongst the members (Etemad and Chu, 2004) and this becomes a prerequisite for Relationship Marketing (Morgan and Hunt, 1994). As a marketing tool, relationship marketing acquires added relevance in the Irish Health Insurance Industry as the traditional marketing mix like product, promotion, place and price can play only a limited role here due to tightly controlled state policy, geographical limitations and the current economic condition.
One of the biggest advantages of relationship management is customer loyalty which is linked to customer life time value (Peppers and Rogers, 2004). Frederick Reichheld is credited for his extensive research on customer profitability and for the suggestion that most customers are profitable only from the second year onwards and customer life time value grows over a period of time (Reichheld, 1996).

Though Fredrick Reichheld's research may be relevant for most of the industry, it will be applicable to Health Insurance Industry only when there is a complete risk equalisation scheme to remove the disincentive in insuring older customers.

When a customer is socially engaged and influential in her circle, then she can provide the organisation with indirect value through referrals (Greenberg, 2009a). Studies by Kumar et al (2007) have shown that though the number of customers who are willing to make referrals can be high, the percentage that actually does can be far lower. This study also showed that the customers who give most business are usually not the best marketers; in other words the most loyal customers are not the most valuable ones. Their study also recommends dividing the customers into Champions (high life time and referral value), Affluent (high life time value and low referral value), Advocates (low life time value and high referral value) and Misers (low live time and low referral value) with a view to identify the customers who need to be encouraged and those who need to be nudged to make more recommendations.

The development of CRM is the result of integrating Relationship Marketing into a total customer management framework by making use of the latest developments in information technology (Lancaster and Reynolds, 2002). It increases the customer value (Peppers and Rogers, 2004) by understanding, anticipating and managing the needs of current and potential customers (Brown, 2000) and by collecting information about the customers and using that to enhance customer experience and foster long term relationships (Bennet, 
2008). According to Paul Greenberg (2010), the traditional CRM strategies which are primarily concerned in managing relationships differ from Social CRM strategies which treat the customer as a partner who can add value to the organisation. Bob Warfield (2009) considers this a paradigm shift from a call centre model type of relationship controlled by the organisation to a model where the control is handed over to the customer. There is also a growing realisation that the customer can be a partner in creating value for the organisation. In their essay 'Co-Opting Customer Competence', C.K.Prahald and Ramaswami (2000) suggest that organisations should include customers as a part of the extended enterprise by engaging them in an active, explicit and ongoing dialogue, mobilising customer communities, managing their diversity and engaging them in co-creating personalised experiences (C.K.Prahalad and Ramaswamy, 2000;p 3).

\section{Current Market Analysis}

A report compiled by Amas in association with the Irish Internet Association comments that Facebook is most effective in B2C context whereas Linkedin is effective in generating leads and building awareness to sales professional and hence valuable in B2B relationship building. It considers Twitter very effective in customer service, special offers and crisis communications (O'Toole, 2010). Countrywise statistics from facebakers.com which provides daily updates on Facebook usage reveals that there are 1.6 Million active Facebook users in Ireland (Candytech, 2010 ). This is $37.9 \%$ of the total population and $67.34 \%$ of the total online users in Ireland. It also reports that $96 \%$ of these Facebook users are below 55 years and $89 \%$ are below 45 years. This is important in the light of the previous research showing the claim cost acceleration trend after the age of 50 years.

\section{Expert's View on Level of Influence}

Experts are of the opinion that Social CRM allows for the creation of a stronger bond between customers and organizations. However, the quality of relationships built over a social media network is a major concern as it can often be light and not based on trust. In a community rated market, intergenerational support is essential for absorbing the losses on account of insuring older customers by profit generated from insuring younger customers. Social Media has tremendous potential for attracting a young population. This feature can be used to great advantage for targeting marketing efforts towards the younger segment. Its value is also appreciated in building relationships in a B2B context which can be best put to use in employer sponsored group schemes. For these reasons the level of influence is deemed to be Positive, strong.

\section{Technological Capabilities}

\section{Literature Review}

Organisations realised the importance of Social CRM when social media applications brought about a revolution in participatory communications, building communities and creating and sharing information (Postman, 2009). Though Facebook, Myspace, Flickr, Twitter, LinkedIn and Youtube are some of the known social networks, there are a number of other public and private social networks providing various niche services to its members. Organisations are looking for ways to track the flow of knowledge passing through these social networks. Business wants to be naturally present where their customers are. According to John Hagel of Deloitte Centre for Edge Innovation, the convergence of pervasive connectivity, maturity of mobile devices as access points and near zero latency of transmissions creates a rich flow of knowledge (Ross, 2009). He argues that the source of economic value is shifting from stocks of knowledge to flows of knowledge. An organisation can learn by participating in this flow as it gives real time feedback as to how the organisation is doing externally in terms of its customer base and internally in terms of its operations. The challenge, according to Ross, is in determining which flow deserves attention and at what point in time filtering these flows becomes the key basis of competition and value creation in the future. Studies by Richard Hackathorn have shown how organisations 
can gain value by reducing latency by operational business intelligence (Davis, 2005). Though this study is based on Internal Business events, its hypothesis is relevant to the identification of external and internal flows which can potentially develop into a significant business event. With Social CRM's capability to integrate and analyse the internal and external flow of knowledge with near zero transmission latency, the reduction in the overall latency achieved could prove very beneficial to an organisation.

Social CRM acquires a strategic dimension when social media users admit a stronger connection with organisations present in social media space as revealed by Cone Marketing Survey (Cone, 2008)). According to Paul Greenberg, when such an evidence is present, it should be a natural choice for organisations to provide social media tools which can help them in social sales, social marketing and social customer support (Greenberg, 2009b). Social CRM tools normally provides for discussion forums, message boards, posting comments, polls and voting, surveys, reviews, rating, chat, blogs, wikis, bookmarking, tagging and search (Sarner et al., 2010). For organisations, Microsoft's white paper (2010) 'CRM and Social Networking: engaging the Social Customer' lists the following benefits: identifying key influencers, automatic tracking of conversations, analysing sentiments, keeping track of competitors' public conversation, identifying sales prospects and monitoring social networks for keywords, complaints and issues.

For Social CRM to be effective, the organisation's customer base should have reached a level of technological maturity. The idea of a social technological ladder was propounded by Forrester Research's William Band and Natalie L Petouhoff (2010) in their article 'Social Media Goes Mainstream' . The article suggests surveying a company's customer base to assess the social computing behaviour and attitudes. It suggests that the organisations assess whether prospects and customers are willing to comment on blogs, contribute content to online forums or wikis, or view online video segments and use the resulting segment profiles to design interaction plans that align with their current social behaviours and preferences.

The major obstacles identified by a Deloitte's survey (2009) in making online communities work are getting people to engage and participate, attracting people to the community and getting people to keep coming back. A study of Social Media Technology Acceptance Model by the University of Reading found that the Web 2.0 features (ease of networking, ease of participation and ease of collaboration) coupled with familiarity, care, information sharing, and perceived trustworthiness are the main factors which influence Social CRM acceptance (Askool and Nakata, 2010). Jennifer Preece and Ben Shneiderman (2009) take this idea a step further and develop a Reader to Leader framework in their article on motivating technology mediated social participation. They suggest that people can be motivated to move from readers to leaders based on usability and sociability factors and participants who deepen their commitment by making repeated contributions or significant collaborations may grow loyal to their social connections and take on leadership efforts to strengthen their community.

\section{Experts View on Level of influence}

Experts view the capability of Social CRM in providing real-time market data, intelligence and feedback as very attractive for organisations. Social CRM's analytical capability to identify key influencers, analyse sentiments and react to new announcements and developments are also seen as very valuable to organisations. The technological environment discussed above and the technical capabilities look promising and therefore a Strong, moderate score is proposed.

\section{Business Objective}

\section{Literature Review}

Charlene Li and Josh Bernoff (2008) have examined CRM 2.0 capabilities with a view to determining which business function can benefit from Social CRM and they have observed that CRM 2.0 capabilities can 
benefit Market Research, Marketing, Sales, Support and Product development.

Organisations mainly use social CRM for marketing, customer support and sales. According to a Deloitte survey (2009), marketing is the primary reason why organisations adopt Social CRM followed by creating value for the brand and direct sales. This is on account of Social CRM's capability in generating word of mouth marketing, increased customer loyalty and increased product or brand awareness. It can interact with Social Media and interpret the activities of the individual and the data in their profile for offer optimisation (Greenberg, 2010). Though traditional advertisements can be purchased, the word-of-mouth publicity generated by social networks needs to be earned and it can happen only if the marketing efforts by the organisation are genuinely useful to individuals who initiate or sustain the word-of-mouth conversations. One of the ways to do that would be to confer social importance to such individuals (Zeisser, 2010).

For customer support, Social CRM can scan social media communities to find customer complaints and then analyse the emotional depth (good or bad) of the complaints. The outcome of this exercise can be an automatic alert to the customer service agent to notify them of the complaint. The complaint can also be promoted to the community for providing a solution. If an answer is found, then it becomes part of the company customer service knowledgebase (Greenberg, 2010).

In sales, the internal analysis based on previous trends and similar deal situations can be combined with the external analysis based on profile information from social networks like LinkedIn or Facebook to form a comprehensive view of the opportunity and factors that might affect the sales (Greenberg, 2010).

\section{Current Market Analysis}

HIA's Health Insurance comparison website (2010b) shows close to 200 plans a customer can choose from. With the tendency of insurers to create a 'selfselection mechanism', choosing the right plan would require careful consideration of the benefit it offers. This can be a bit daunting for the average customers. Here, Social CRM can play an important role in guiding customers in choosing the right plan and reinforcing their trust and confidence in the organisation.

\section{Experts View on Level of Influence}

The Health Insurance Industry is not particularly suited for turning customers into problem solvers as customers expect clarity in communication which can only be given by a professional agent. Organisations can generate good will by involving customers in innovations and ideas. It can also be a communication channel for receiving early feedback on new products and services which it intends to introduce. Generating word of mouth referrals, creating loyalty, retention and growth, and deriving value as an alternate channel of communication are some other potential benefits of Social CRM as identified by the experts. The marketing potential of Social CRM offers a Positive, strong influence.

\section{Cost Benefit Studies}

\section{Literature Review}

There are not many published cost benefit studies on Social CRM probably because organisations are still experimenting with it and are not yet ready to quantify the outcome. The number of active users and the frequency of posting comments are the most frequently used measure of success. In any large online community, a large number of people would be 'lurkers' who observe the online community but do not participate in any overt manner by posting, contributing or communicating within the members of the community. Studies by Nonnecke and Preece (1999) disprove the preconceived notion that one must be an active poster to be part of community. They found that even lurkers can have strong sense of community and suggest that giving lurkers recognition as valid participants will benefit both lurkers and the community as a whole. In a more recent study by MIT (Takahashi et al., 2007), the authors regard lurkers not as a target to be reduced, but one to be promoted and observe that lurking might have positive 
impacts on the management of an online community. This is believed to be true due to the fact that a considerable number of lurkers use or propagate information gained from online communities in their outside environment and hence they have high value in word of mouth communication through more traditional channels.

Social CRM researchers generally avoid the topic of return on investment on Social CRM as many consider intangible benefits far exceeding tangible benefits. However Deloitte's Ed Moran thinks that in a customer service context with its tremendous opportunity to leverage the relationship-building and community spirit of social networks, the cost of customer support is easy to calculate. When a customer has a problem resolved in an online community, either by a corporate representative or especially by another community member and as a result the customer does not call the support line, the cost savings can be measured (Soat, 2010).

With a three year time frame for analysis, Forrester suggests a figure of 99\% ROI from customer service online community projects for small and medium sized call centres which use federated searches, attract super users and allow agents to access the customer community to engage with them and demonstrate a genuine interest in a user's opinion (Petouhoff et al., 2009).

\section{Expert's View of Level of Influence}

Experts are of the opinion that most of the benefits derived by the business are intangible and it is difficult to put a value against these benefits. The cost benefit study discussed in the Literature Review has limitations in terms of its relevance to the Irish Health Insurance Industry which is more orientated towards using Social CRM as a marketing tool instead of using it for customer support of online communities. It is unlikely that a cost benefit analysis would be the main driver for implementation of a Social CRM strategy as there are important considerations other than cost to be taken into account. Therefore, this factor would exert only a Positive, weak influence.

\section{Market Trends}

\section{Literature Review}

Organisations watching competitor's space to avoid unexpected surprises would find it hard to keep away from Social CRM when studies point to its gaining maturity in the market. According to a Deloitte survey (2009) of more than 400 US companies, $94 \%$ of respondents intend to maintain or increase their investment in enterprise social networking tools, $20 \%$ of the respondents have instigated formal 'ambassador' programs which give outsiders preferential treatment in return for being more active in the community and $39 \%$ of the respondents indicated that more full-time people are being deployed to manage the communities. Organisations may also be influenced by the growing number of Social CRM case studies, which broadcast the positive outcome from its usage as well as the danger of not having an effective intervention tool like Social CRM in protecting its brand image, in the event of a negative campaign in online communities.

In July 2009, the Altimeter group released a study that analysed the 100 most valuable brands and how they engage across 11 different online social media venues including Facebook, Twitter and YouTube. It ranked Starbucks in first place, followed by Dell and eBay (Rubel, 2009). According to C.K. Prahalad (2010), companies identify best practices, particularly those of market leaders, and try to implement them. Such benchmarking has a role to play in business. It may allow enterprises to catch up with competitors, but it will not turn them into market leaders. Organizations become winners by spotting big opportunities and inventing next practices. Starbucks' social media experiment should be looked at from this aspect.

Starbuck maintains six online community touch points. A Facebook page, a Twitter feed for customer service, a YouTube channel for posting videos of brand promotion and its charitable work, an Idea forum for receiving ideas from its customers, a social network to get people to take action by supporting events that enrich their communities and a Flickr 
account for posting photos. This underlines Starbucks CEO Howard Schultz's vision, which he articulates in terms of the need for human connection and sense of community in the society we are living and the desire to constantly create excitement that provides differentiation and separation in the marketplace (Ignatius, 2010).

Emily Bryson York, who studied Starbucks' social media phenomenon, reckons that Starbucks has more than 5.7 million Facebook fans and 775,000 Twitter followers, 180,000 registered users in its Idea forum and more than 80,000 ideas on MyStarbucksIdea.force.com (York, 2010). Starbucks does not make any money directly from its social media efforts but what it does is reinforce and deepen relationships with existing customers (Quenqua, 2010).
A recent research on German Health Insurance companies using Web 2.0 (Blinn et al., 2010) brings some interesting insights. The study shows that cost savings and competitiveness are the two main reasons for German Health Insurance companies to provide high quality information via the Internet. Since insurance contributions in Germany are harmonized to a certain level, the differentiating factors for the companies are the services they provide. Three major attractions discussed in the study for Web 2.0 implementation are pre-sale consultation, co-design of the products and a playful and interactive way of providing contents.

\section{Current Market Analysis}

Health Insurance is a hot topic in Ireland and the public interest in this topic is only surpassed by people in the United States of America. A search on Google Insight produces the following graph.

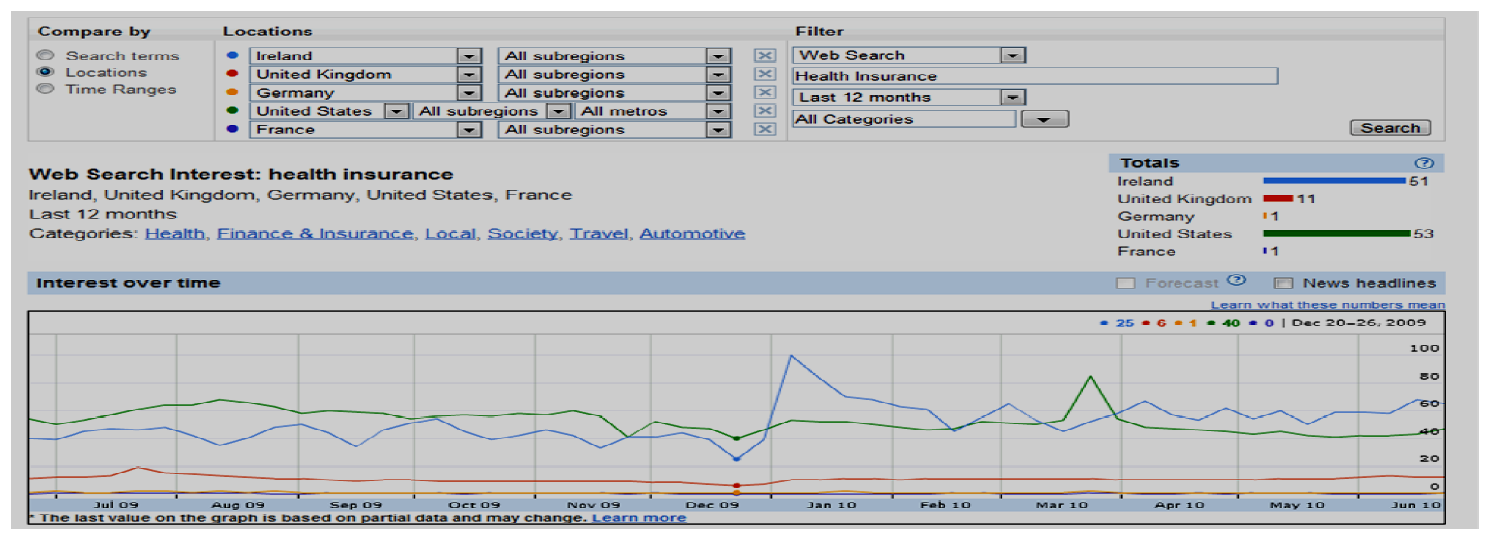

Fig. 4: Public Interest in Health Insurance

According to Google Insight, the numbers on the graph reflect how many searches have been done for a particular term, relative to the total number of searches done on Google over a period of time. The data are normalised and presented on a scale of 0 to 100 . It can be seen from the graph that the average interest shown on the topic of Health Insurance in Ireland is $51 \%$ which is second only to the $53 \%$ figures reported by the US. Even though the search was repeated for other countries in Europe, no other country could report a figure that came anywhere near to these figures (The graph can show only 5 countries at a time).

Experts View on Level of Influence

Experts generally have a positive view on Social CRM's possibilities and highlight case studies to underline how different industries make the best use of this emerging channel of communication. There is a general consensus that organisations will experiment with Social CRM in the near future. Eventually, a Social CRM strategy will become the objective for organisations who wish to promote loyalty and trust. The Experts highlight the 
growing popularity of Social CRM. In the current economic and industrial climate, Health Insurance is an important topic for people in Ireland. It is likely that an initiative such as Social CRM, if introduced in this climate, will be immediately noticed potentially reducing the effort required in creating a committed fan base. Therefore, the Level of Influence is deemed to be Positive, moderate.

\section{Issues and Risks}

\section{Literature Review}

Understanding the risks and pitfalls helps an organisation in facing up to the problems. It can also be a major influence on a Social CRM strategy. According to the Information Systems Audit and Control Association ISACA (2010), organisations are exposed to the following risks from social media:

- Corporate Social Media Presence: The risks include data theft and leakage, exposure to customers through fraudulent or hijacked corporate presence; organisations loss of control (legal right) on information posted to the social media site and increased customer service expectations leading to customer dissatisfaction.

- Employee's Personal Use of Social Media: The risks here include privacy violations, reputational damage, loss of competitive advantage by spilling company secrets, data theft and data leakage.

In terms of specific legal issues, the article 'When marketing through social media, legal risks can go viral' from Melissa Landua Steinman and Mikhia Hawkins (2010) is an important guideline for organisations. This article looks at a number of issues such as third party abuse of business trademarks and copyrights, the need for monitoring and screening of social media content and how to effectively address privacy and data security issues. The main theme that comes out of this article is the importance of proper guidelines and controls such that organisations can implement their own terms and conditions.
Many organisations bring specific guidelines on social media engagement to their employees and encourage them to use it for more successful business relationships. This optimism and confidence is visible in Intel's social media guidelines when it says "Let's share with the world the exciting things we're learning and doing and open up the channels to learn from others" (Intel, 2010).

\section{Current Market Analysis}

There are some serious concerns in Implementing Social CRM but there is also an opportunity to enhance the image and reputation of the organisation. Organisations need to have a balanced approach in handling the criticism and negative views. To quote Intel's guidelines on Social media usage (2010): "If the content is positive or negative and in context to the conversation, then we approve the content, regardless of whether it's favourable or unfavourable to Intel. But if the content is ugly, offensive, denigrating and completely out of context, then we reject the content". In terms of privacy and security issues, guidelines like those issued by ISACA should help organisations in facing up to the challenge.

\section{Expert's View on Level of Influence}

Complacency, negative comments and lack of control over content are the main issues discussed by experts. Tackling issues immediately, acknowledging genuine error and highlighting how social CRM helped in resolutions for all to see are some of the methods discussed to address these issues. Experts are also of the view that explosive situations, if handled diplomatically, could highlight the maturity of the organization to those following the discussion.

The overriding privacy concern in the Health Insurance sector is measured by assigning a measure of negative influence on the Social CRM Business Case. The risk mitigation methods discussed in the Literature Review should address some of these concerns resulting in a Negative, weak influence. 


\section{Summary of Business Case Analysis}

In summary, experts believe that the implementation of Social CRM can largely benefit the Irish Health Insurance Industry.
They base it on the fact that nine out of the ten external environmental factors considered for this study resulted in a positive influence and most of these are categorised under strong or moderate.

Table 3: External environmental facto's Level of influence on the business case

\begin{tabular}{|l|l|l|}
\hline External Environmental Factors & \multicolumn{2}{|c|}{ Level of Influence } \\
\hline 1. $\quad$ Nature of Business & Positive & Moderate \\
\hline 2. Demographic Profile & Positive & Moderate \\
\hline 3. Market Forces & Positive & Strong \\
\hline 4. Cultural Dimensions & Positive & Strong \\
\hline 5. Social Factors & Positive & Strong \\
\hline 6. Technological Capabilities & Positive & Moderate \\
\hline 7. Business Objectives & Positive & Strong \\
\hline 8. $\quad$ Cost/Benefit Studies & Positive & Weak \\
\hline 9. Market Trends & Positive & Moderate \\
\hline 10. Issues and Risks & Negative & Weak \\
\hline
\end{tabular}

\section{Conclusion}

In conclusion, it is suggested that Social CRM is a sound business strategy for the Irish Health Insurance Industry mainly due to its appeal to the young generation. This is one market segment every insurer would like to retain and grow due to its profitability. The Literature Review has revealed that in the absence of risk spreading, the insurer can get into a "death spiral" type of situation. In a community rated market, the insurer needs to have a sufficient number of low risk (young policy holders) to spread the risk of insuring high risk older policy holders.

The Literature Review has also shown why adverse risk selection is generally absent in an employee sponsored group segment and how marketing and administrative efficiencies can contribute to higher profit in this segment. However, insurers are also limited by their ability to interact directly with the policy holders in this segment as their interaction typically would be with an authorised person appointed by the employer for maintaining employees' policies. This confines the insurer's ability to cross-sell and up-sell its products and generate a higher profit. Here, a nonconventional and innovative approach is required to engage the policy holders. The
Literature Review has also highlighted the importance of creating multiple channels of communication with customers, which will help them in choosing the most comfortable channel for communicating with the organisation. Social CRM could be an effective channel in this segment for policy holders to engage with the insurer directly without involving their employers.

This research has also pointed out how Social CRM can promote a sense of community among users. It has highlighted the advantages of creating an accessible support structure possibly maintained by an ambassador customer for creating trust, loyalty and perhaps, additional sales and revenue. This model has a likely application in larger employee sponsored group segments whereby a suitable policy holder within each large group can be assigned the ambassador customer role.

Experts agree on how easy it is to form target clusters in a Social CRM space and there is tremendous scope for its application in the Health Insurance business. For instance, Social CRM can also be used to create a sense of prestige and status among policy holders who buy premium plans by creating a community of premium plan customers who would be 
eligible for a superior service and additional incentives.

Hofstede's cultural dimension studies have revealed that people in Ireland are very open to innovation and change and at the same time critical of irresponsible behaviour. This cultural aspect as well as the high social network usage in Ireland should encourage organisations to use Social CRM as an innovative channel for customer interaction as there is a higher probability that this initiative will find acceptance from its customers.

In recent times, a large number of insurance products were introduced by insurers in Ireland, targeting specific market segments. Competition alone cannot justify the number and frequency of these product launches. It is likely that the insurers are desperately looking for a winning formula to maximise the profit and as a result, tend to experiment by tinkering with the product and benefit design. The absence of an effective feedback loop from customer to insurer makes this process more time consuming and costly. This research has highlighted the possibility of improving this process by implementing Social CRM to facilitate receiving more timely feedback from online customer communities.

Organisations would like to receive timely market intelligence and there is a much higher expectation when Social CRM is implemented. However, experts have highlighted the need for creating the necessary structure and framework for processing this flow of information. It is likely that implementing Social CRM should activate this process within the organisation and improve an organisation's overall capability in handling market intelligence and also strengthen their issue prevention/intervention mechanism.

Privacy and security are of utmost importance to the Health Insurance Industry. This was one of the concerns of experts while discussing the implementation of Social CRM in the Health Insurance Industry. It appears that this particular concern will limit the use of Social CRM as a Customer Support tool in the Health Insurance Industry. Insurers might want to provide this support on a one to one basis in a secure and confidential environment. However, there is a strong incentive to implement Social CRM in marketing, sales and market research activities. A Social CRM implementation is relatively less expensive than a number of other enterprise wide applications such as supply chain management, human resource management etc., as it would be usually built on top of an existing CRM module. It is unlikely that the cost will be a main concern in deciding whether or not to implement Social CRM; rather it would be the existence or absence of a justifiable business case. As such, in the case of the Health Insurance Industry, the business case is strong enough to consider its adoption in the current economic and regulatory environment.

In the social media space, the organisation and its customers coexist and the resultant vulnerability of the organisation could give rise to the fear of loss of control. It appears that this would be the nature of the game in the future and as pointed out by Howard Schultz, CEO of Starbucks, by facing up to this challenge, organisation can in fact benefit by gaining further trust from its customers.

\section{References}

1. American Academy Of Actuaries. 2001. Risk classification in voluntary individual disability income and long term care Insurance. Available: http://www.actuary.org/pdf/health/issue_ genetic_021601.pdf [Accessed 17th March 2010].

2. Askool, S. S. \& Nakata, K. Scoping study to identify factors influencing the acceptance of social CRM. Management of Innovation and Technology (ICMIT), 2010 IEEE International Conference on, 2-5 June 2010 2010. 1055-1060.

3. Band, W. \& Petouhoff, N. L. 2010. Social CRM Goes Main Stream [Online]. Forrester Research Inc. Available: http://www.forrester.com/rb/Research/to pic_overview_social_crm_goes_mainstream 
/q/id/55884/t/2 [Accessed 16 March 2010.

4. Barrett, S. D. 2000. The economics of competition in health insurance - The Irish case study, Trinity College, Dublin.

5. Bennet, J. T. 2008. Customer Relationship Management (CRM) Theory and Practice.

6. Bertiko, J,2008, Health Insurance Market Rating Practices, The RAND Corporation

7. Blinn, N., KUHNE, M. \& NUTTGENS, M. Are Public and Private Health Insurance Companies Going Web 2.0? - A Complete Inventory Count in Germany. System Sciences (HICSS), 2010 43rd Hawaii International Conference on, 5-8 Jan. 2010 2010. 1-9.

8. Breaudun, D. D. \& Donnellan, E. 2010. Sale of VHI will not keep prices down - FG. Irish Times, 29th May 2010.

9. Brian, B. N. N. 2006. The Interaction of Public and Private Health Insurance: Ireland as a Case Study. Geneva Papers on Risk \& Insurance - Issues \& Practice, 31, 633-649.

10. Brown, S. A. 2000. Customer relationship management : a strategic imperative in the world of e-business, New York; Chichester, Wiley.

11. Buchmueller, T. \& Dinardo, J. 2002. Did community rating induce an adverse selection death spiral? Evidence from New York, Pennsylvania, Connecticut. Available: http://www.jstor.org/pss/3083333 [Accessed 4th April 2010].

12. Buckley, D. 2010. Going Dutch: Fine Gael's health plan. Irish Examiner, $27 \mathrm{Feb}$ 2010.

13. Bundorf, M. 2010. The effects of offering Health Plan Choice within Employment based Purchasing Groups. Journal of Risk and Insurance, 77, 105.

14. C.K.Prahalad \& Ramaswamy, V. 2000. Co-Opting Customer Competence. Customer
Relationship Management. Hardward Business Review.

15. Candytech. 2010. Facebok Statistics Ireland [Online]. Candytech. Available: http://www.facebakers.com/countrieswith-facebook/IE/ [Accessed 27th June 2010.

16. Canzer, B. 2006. E Business: Strategic thinking and practice. Houghton Mifflin Company.

17. Central Statistics Office Ireland. 2010. Consumer Price Index [Online]. Available: http://cso.ie/releasespublications/docume nts/prices/current/cpi.pdf [Accessed 20 June 2010.

18. Chollet, D. J. 1998. Understanding Individual Health Insurance Markets. Kaiser Family Foundation.

19. Claxton, G. 2002. How Private Insurance Works A Primer, Kaiser Family Foundation.

20. Collins, S. R. 2007. employer-based health insurance past, present, and future. hfm (Healthcare Financial Management), 61, 34-37.

21. Cone. 2008. 2008 Business in Social Media Study [Online]. Cone. Available: http://www.coneinc.com/content1183 [Accessed 7th July 2010.

22. Connelly, L. B. \& Brown, I. I. I. H. S. 2010. Private Health Insurance in Australia: Community Rating, but at What Price(s)? Journal of Health Care Finance, 36, 80-92.

23. Coyle, R. G. 2004. Practical strategy : structured tools and techniques, Harlow, Financial Times Prentice Hall.

24. Davis, J. R. 2005. Right-Time Business Intelligence Optimizing the Business Decision Cycle [Online]. Beye Research. Available:

http://www.beyeresearch.com/study/214

9 [Accessed 18th July 2010.

25. De Mooij, M. \& Hofstede, G. 2010. The Hofstede model. International Journal of Advertising, 29, 85-110. 
26. Dealtry, T. R. 1992. Dynamic SWOT analysis : developer's guide : when looking to the future look for the opportunities and threats and consider your strengths and weaknesses, Birmingham (Prince's Corner, Harborne Park Road, Harborne, Birmingham. B17 0DE), Dynamic SWOT Associates.

27. Deloitte. 2009. Tribalization of Business Study. Available: http://www.deloitte.com/assets/DcomUnitedStates/Local\%20Assets/Documents /TMT_us_tmt/us_tmt_TribofBusFlipBook_1 00609.pdf [Accessed 16 June 2010].

28. Department Of Health And Children 1999. White Paper - Private Health Insurance. Stationery Office.

29. Department of Health And Children. 2010. Health Insurance Market Reforms Qustion and Answers [Online]. Available: http://www.dohc.ie/issues/health_insuran ce/health_insuranceqanda.pdf?direct $=1$ [Accessed 5th July 2010.

30. Dones, J. 2010. Harney plans new risk equalisation measures. Sunday Tribune, 21st Feb 2010.

31. Dormont, B., Grignon, M. \& Huber, H. 2006. Health expenditure growth : reassessing the threat of ageing. Available: http://hal.inria.fr/docs/00/18/16/05/PDF /Dormont-Grignon-Huber-HE.pdf [Accessed 23 April 2010].

32. Eggleston, K. 2000. Risk Selection And Optimal Health Insurance-Provider Payment Systems. Journal of Risk \& Insurance, 67, 173-196.

33. Etemad, H. \& Chu, H. 2004. The dynamic impact of regional clusters on international growth and competition: some grounded proposition. International entrepreneurship in small and medium size enterprise. Edward Elgar Publishing Limited.

34. Feldman, R. \& Dowd, B. 2000. Risk segmentation: goal or problem? Journal of Health Economics, 19, 499-512.
35. Fiona, R. 2009. Try to keep covered, if you can. The Irish Times (1921-Current File).

36. Foubister, T., S. Thomson, et al. (2006). Private medical insurance in the United Kingdom. Copenhagen, World Health Organization.

37. Fürhaupter, R. \& Brechtmann, C. 2003. A survey of the Private Health Insurance in Germany. Available: http://www.actuaries.org/EVENTS/Congr esses/Cancun/health_subject/health_28_fu rhaupter.pdf [Accessed 9th May 2010].

38. Gartner. 2010. Gartner Reveals Five Social Software Predictions for 2010 and Beyond [Online]. Available: http://www.gartner.com/it/page.jsp?id=1 293114 [Accessed 8th July 2010.

39. Greenberg, P. 2009a. Managing Social Customers for Profit. CRM Magazine, 13, 48-48.

40. Greenberg, P. 2009b. Social CRM Comes of Age [Online]. Oracle. Available: http://www.oracle.com/us/products/appli cations/siebel/036062.pdf [Accessed 15th July 2010.

41. Greenberg, P. 2010. CRM at the speed of light : social CRM strategies, tools, and techniques for engaging your customers, New York, McGraw-Hill.

42. Grootaert, C. \& Bastelaer, T. V. 2002. Social Capital from Definition to Measurement. Understanding And Measuring Social Capital. The World Bank.

43. Hall, M. A. 1994. Reforming Private Health Insurance The AEI Press

44. Health Insurance Authority. 2010a. Consultation Paper on Risk Equalisation in the Irish Private Health Insurance Market. Available:

http://www.hia.ie/assets/files/publication s/Risk_Equalisation/Consultation\%20Pape r\%20on\%20Risk\%20Equalisation\%20June $\% 202010 . p d f$ [Accessed 10th July 2010]. 
45. Health Insurance Authority. 2010b. Health Insurance Comparison [Online]. Health Insurance Authority, Ireland. Available: http://www.hia.ie/ci/healthinsurance-comparison/searchform/compare-against/ [Accessed 22nd July 2010.

46. Hitt, M. A., Ireland, R. D., Hoskisson, R. E. \& Hitt, M. A. S. M. C. A. G. 2007. Management of strategy : concepts and cases, Australia ; United Kingdom, Thomson South-Western.

47. Hofstede, G. 2010. Greet Hofstede Cultural Dimensions [Online]. itim International. Available: http://www.geerthofstede.com/index.shtml [Accessed 6th June 2010.

48. Hoppe, M. H. 2004. An interview with Geert Hofstede. Academy of Management.

49. Ignatius, A. 2010. "We Had to Own the Mistakes". Harvard Business School Publication Corp.

50. Independent, I. 2008. Supreme Court Strikes Down Risk Equalisation Scheme. Irish Independent, July 162008.

51. Insight Statistical Consulting. 2008. The Private Health Insurance Market in Ireland.

52. Intel. 2010. Intel Social Media Guidelines [Online]. Intel Corpration. Available:

http://www.intel.com/sites/sitewide/en_u s/social-media.htm [Accessed 18th July 2010.

53. ISACA. 2010. Social Media: Business Benefits and Security, Governance and Assurance Perspectives [Online]. ISACA, USA. Available: http://www.isaca.org/KnowledgeCenter/Research/Documents/SocialMedia-Wh-Paper-26-May10-Research.pdf [Accessed 16th July 2010.

54. John, C., Michael, C., David, H., Tony, J. \& Jimmy, J. 2002. Report of Working Group on Risk Equalisation [Online]. Society of Actuaries in Ireland. Available: http://web.actuaries.ie/Events $\% 20$ and $\% 2$
0Papers/Events\%202002/2002-0501_Risk\%20Equalisation/Risk\%20Equalisa tion\%20Report\%20-\%202002.pdf [Accessed 15 Mar 2010.

55. Joseph Pine, Don Peppers \& Rogers, M. 1995. Do you want to Keep your customers forever? Hardward Business Review, 103115.

56. Kennedy, A. 1996. Private Health Insurance in Ireland. European Journal of Health Law, 3, 345-357.

57. Khushman, S., Todman, A. \& Amin, S. The Relationship between Culture and Ebusiness Acceptance in Arab Countries. Developments in eSystems Engineering (DESE), 2009 Second International Conference on, 14-16 Dec. 2009 2009. 454459.

58. Kifmann, M. 2002. Insuring premium risk in competitive health insurance markets J.C.B.Mohr (Paul Siebeck) Tubingen.

59. Kumar, V., Petersen, J. A. \& Leone, R. P. 2007. How Valuable Is Word of Mouth? Harvard Business Review, 85, 139-146.

60. Kwon, W. J. \& Skipper, H. D. 2007. Risk management and insurance : perspectives in a global economy, Oxford, Blackwell.

61. Lancaster, G. \& Reynolds, P. 2002. Marketing made simple. Elsevier Science.

62. Li, C. \& Bernoff, J. 2008. Groundswell: Winning in a world transformed by social technologies, Harvard Business Press.

63. Mark, J. B. 1992. Evidence of Adverse Selection in the Individual Health Insurance Market. Journal of Risk and Insurance (1986-1998), 59, 13.

64. Marquis, M. S. \& Buntin, M. B. 2006. How Much Risk Pooling Is There in the Individual Insurance Market? Health Services Research, 41, 1782-1800.

65. Marse, 2011. Dutchhealthcare reformatthe crossroads [Online]. Available: http://healthcarecostmonitor.thehastingsc enter.org/files/2011/06/Maarse-Dutch- 
health-care-reform-at-the-crossroads-longversion1.pdf [Accessed 26th Feb 2014.

66. Mcdonnell, O. \& O'donovan, O. 2009. Private health insurance as a technology of solidarity? The myth of 'community' in Irish healthcare policy. Irish Journal of Sociology, 17, 6-23.

67. Mechanic, D., LYNN B, R., C.CLOBY, D. \& R.KNICKMAN, J. 2005. Policy Challenges in Modern Health Care. Rutgers University Press.

68. Microsoft. 2010. CRM and Social Networking: Engaging the Social Customer [Online]. Microsoft Dynamics. Available: http://crm.dynamics.com/docs/CRM_and_ Social_Networks.pdf [Accessed 25th July 2010.

69. Morgan, R. M. \& Hunt, S. D. 1994. The Commitment-Trust Theory of Relationship Marketing. Journal of Marketing, 58, 20.

70. Mossialos E, et al. (2002). Funding health care options for Europe, European Observatory on Health Care System Series, Open University Press

71. Moseley, G. B. 2009. Managing Health Care Business Strategy. Jones and Barrlett Publishers, LLC.

72. Nonnecke, B. \& PREECE, J. 1999. Shedding Light on Lurkers in Online Communities.

73. Neuhaus, W, 1995, Community rating and equalisation, University of Copenhagen and MIRA Consultants Ltd (Sydney)

74. O'toole, A. 2010. State of the Net [Online]. Irish Internet Association in Collaboration with amas. Available: http://www.iia.ie/resources/resource/1/s tate-of-the-net/ [Accessed 27th June 2010.

75. Ofcom. 2008. Social Networking A quantitative and qualitative research report intoattitudes, behaviours and use [Online]. Office of Communcations, UK. Available: http://www.ofcom.org.uk/advice/media_li teracy/medlitpub/medlitpubrss/socialnet working/report.pdf [Accessed 03 Feb 2010 2010].
76. Office Of The Technology Assessment 1984. Medical Technology and cost of the Medicare program. Washington DC. US Congress.

77. Peppers, D. \& Rogers, M. 2004. Managing customer relationships : a strategic framework, New Jersey ; [Chichester], Wiley.

78. Percival, G. 2010. Bid to allay concerns after Quinn Insurance administration. Irish Examiner, 31st March 2010.

79. Percy, A. M. 2000. Community rating and regulatory reform in health insurance markets. Ph.D. 9989636, University of Pennsylvania.

80. Petouhoff, N. L., Gliedman, C., Band, W. \& Magarie, A. 2009. The ROI of Online Customer Service Communities [Online]. Forrester. Available: http://www.forrester.com/rb/Research/r oi_of_online_customer_service_communitie $\mathrm{s} / \mathrm{q} / \mathrm{id} / 48002 / \mathrm{t} / 2$ [Accessed 28th May 2010 .

81. Postman, J. 2009. SocialCorp : social media goes corporate, Berkeley, CA, New Riders.

82. Prahalad, C. K. 2010. Best Practices Get You Only So Far. Harvard Business Review, 88, 32-32.

83. Preece, J. \& Shneiderman, B. 2009 Transaction on Human-Computer Interaction: Motivating TechnologyMediated Social Participation.

84. Pricewaterhousecoopers. 2006. Healthy Choice 2006 - The Changing Role of Health Insurer [Online]. [Accessed 17th July 2010.

85. Quenqua, D. 2010. Starbucks' Own Good Idea. Marketing News, 44, 23-25.

86. Reichheld, F. F. 1996. The quest for loyalty : creating value through partnership, Boston, MA, Harvard Business School Press.

87. Rosenau, P. V. \& Lako, C. J. 2008. An Experiment with Regulated Competition and Individual Mandates for Universal 
Health Care: The New Dutch Health Insurance System. Journal of Health Politics, Policy \& Law, 33, 1031-1055.

88. Ross, J. M. 2009. Abandon stocks, embrace flows - a conversation. O'Reilly radar.

89. Rubel, S. 2009. How to build social capital: Innovate early and often. Advertising Age, 80, 14-14.

90. Santerre, R.E. \& Neun, S.P., 2012. Health Economics : Theories, Insights, and Industry Studies. Cengage Learning.

91. Sarner, A., Thompson, E., Mann, J., Dunne, M., Davles, J., Fletcher, C., Alvarez, G. \& Maoz, M. 2010. Magic Quadrant for Social CRM [Online]. Gartner Inc. Available: http://www.lithium.com/pdfs/whitepaper s/Gartner-MQ-Social-CRM-t4OR7RhY.pdf [Accessed 18 July 2010.

92. Schleifer, D. 2012, Expanding the definition of Social CRM [Online]. Available: http://www.destinationcrm.com/Articles/ Web-Exclusives/Viewpoints/Extendingthe-Definition-of-Social-CRM-84164.aspx [Accessed 23 Feb 2013.

93. Schneider, E. 2011, The Main Features of German Private Health Insurance [Online]. Available: http://www.actuaries.org/EVENTS/Congr esses/Cancun/health_subject/health_16_sc hneider.pdf [Accessed 26 Feb 2013.

94. Shi, L. \& SINGH, D. A. 2008. Delivering health care in America: a systems approach. Jones and Bartlett's publications, Inc.

95. Simon, C. 2009. Underwriting profits in Irish insurance fall 83\%. The Irish Times (1921-Current File).

96. Soat, J. 2010. 7 Questions Key To Social Networking Success. InformationWeek, 18.

97. Steinman, M. L. \& Hawkins, M. 2010. When Marketing Through Social Media, Legal Risks Can Go Viral. Intellectual Property \& Technology Law Journal, 22, 1-9.
98. Stickel, D., Mayer, R. C. \& Sitkin, S. B. 2009. Understanding social capital: in whom do we trust? In: BARTKUS, V. 0. \& DAVIS, J. H. (eds.) Social capital: reaching out, reaching in. Edward Elgar Publishing Ltd.

99. Svendsen, G. T. \& Svendsen, G. L. H. 2009. Handbook of social capital : the troika of sociology, political science and economics, Cheltenham, Edward Elgar.

100. Takahashi, M., Fujimoto, M. \& Yamasaki, N. 2007. Active Lurking: Enhancing the value of inhouse online communities through the related practices around the online communities. Available: http://cci.mit.edu/publications/CCIwp200 7-06.pdf [Accessed 25th May 2010].

101. The Health Insurance Authority. 2009. Submission of the Health Insurance Authority to the Oireachtas Joint Committee on Health and Children [Online]. Available: http://www.hia.ie/publication/otheradvisory-reports.htm [Accessed 18 Feb 2010.

102. The Oecd Health Project 2004. Private health insurance in OECD countries, Paris, OECD.

103. Thompson, J. L. \& Martin, F. 2010. Strategic management : awareness \& change, Andover, South-Western Cengage Learning.

104. Thomson S \& Mossialos E, 2010, Health Systems Governance in Europe, Cambridge University Press

105. Thomson, S. \& Mossialos, E. 2009. Private health insurance in the EuropeanUnion. London School of Economics and Political Science.

106. Walsh, B. 2002. McEneaney judgement. Available:

http://www.actuaries.ie/Events\%20and\% 20Papers/Events\%202002/2002-03-

26_McEneaney\%20Judgement/020326_Br endan_Walsh.pdf [Accessed 25th April 2010]. 
107. Warfield, B. 2009. A Social CRM Manifesto: How to succeed with Social CRM Virtuous Cycle. helpstream.

108. Warshawsky, M. J. 1994. Projects of Health Care Expenditures as a Share of the GDP: Actuarial and Macroeconomic Approaches. Available: http://www.ncbi.nlm.nih.gov/pmc/articles /PMC1070007/pdf/hsresearch000530040.pdf [Accessed 23rd April 2010].

109. Williams, G. \& Zinkin, J. 2008. The effect of culture on consumers' willingness to punish irresponsible corporate behaviour: applying Hofstede's typology to the punishment aspect of corporate social responsibility. Business Ethics: A European Review, 17, 210-226.
110. Witter, L. \& Chen, L. 2008. The she spot : why women are the market for changing the world--and how to reach them, San Francisco, Calif., Berrett-Koehler ; London : McGraw-Hill [distributor].

111. Worthington, I. \& Britton, C. 2009. The business environment, Harlow, Financial Times Prentice Hall.

112. York, E. B. 2010. Starbucks gets its Business Brewing again with Social Media. Advertising Age, 81, 34-34.

113. Zeisser, M. 2010. Unlocking the Elusive Potential of Social Networks [Online]. Mckinsey Quarterly. Available: https://www.mckinseyquarterly.com/Unlo cking_the_elusive_potential_of_social_netw orks_2623 15 July 2010]. 